\title{
AN OBSERVATIONAL STUDY OF CLINICAL AND HEMATOLOGICAL PROFILE OF CIRRHOSIS OF LIVER
}

\author{
BIBHU PRASAD BEHERA ${ }^{1}$, MANORANJAN DASH ${ }^{2 *}$ \\ ${ }^{1}$ Department of Internal Medicine, Saheed Laxman Naik Medical College and Hospital, Koraput, Odisha, India. ${ }^{2}$ Department of Chest and \\ TB, Saheed Laxman Naik Medical College and Hospital, Koraput, Odisha, India. Email: drmrdash@rediffmail.com
}

Received: 05 January 2019, Revised and Accepted: 24 February 2020

\section{ABSTRACT}

Objective: Efforts can be made to normalize the hematological parameters so that the morbidity and mortality in these patients could be effectively reduced.

Methods: This observational study was carried out among 69 cirrhosis patients that fulfills the inclusion and exclusion criteria, attended the medicine outpatient department, and admitted in medicine ward of PRM Medical College and Hospital, Baripada, Dist. Mayurbhanj, Odisha, India, from June 2018 to January 2019.

Results: In our study, we had 59 male and 10 female patients with an average age of $49.8 \pm 13.19$ years. About $92.75 \%$ of the patients were alcoholic. Abdominal distension (92.75\%) and ascites (84.06\%) were the most common presenting complaints. Pallor was present in 42 (60.87\%) cases. Splenomegaly was present in 35 (50.72\%) cirrhotic patients. Renal dysfunction was present in 23 (33.33\%) cases. Sixty-six (95.65\%) patients had anemia and 47 (68.12\%) patients had thrombocytopenia.

Conclusions: From this study, we can conclude that, in cirrhosis of liver patients, various hematological changes are very common which need to be identified and corrected early to reduce morbidity and mortality.

Keywords: Cirrhosis, Anemia, Thrombocytopenia, Alcoholic, Non-alcoholic.

(C) 2020 The Authors. Published by Innovare Academic Sciences Pvt Ltd. This is an open access article under the CC BY license (http://creativecommons. org/licenses/by/4. 0/) DOI: http://dx.doi.org/10.22159/ajpcr.2020.v13i4.36862

\section{INTRODUCTION}

The liver is one of the most complex functioning organs with a wide array of functions in human body. It plays a major role in carbohydrate, protein, lipid metabolism, synthesis of plasma proteins and maintenance of immunity (Kupffer cells), inactivation of various toxins, metabolism of drugs, and hormones. The liver has an extremely important role in maintenance of blood homeostasis as it functions as a storage depot for iron, folic acid, and Vitamin B12, secretes clotting factors and inhibitors. Hence, it is not surprising that, in liver diseases, a wide range of hematological abnormalities can be seen.

In general population, global prevalence of cirrhosis from autopsy studies ranges from $4.5 \%$ to $9.5 \%$ [1-3]. Hence, taking the adult population into count, we estimate that more than $\mathbf{5 0}$ million people in the world would be affected with chronic liver disease (CLD). At present, globally, the most common causative factors are alcohol, nonalcoholic steatohepatitis and viral hepatitis. The prevalence of cirrhosis is likely to be underestimated; as almost one-third of the patients remain asymptomatic.

During 2001, the estimated worldwide mortality from cirrhosis was 771,000 people; it was ranked $14^{\text {th }}$ and $10^{\text {th }}$ as the leading cause of death in the world and in developed countries, respectively [4]. Deaths from cirrhosis have been estimated to increase and would make it as the $12^{\text {th }}$ leading cause of death in 2020 [5].

CLD in the clinical context is a disease process of the liver that involves progressive destruction and regeneration of the liver parenchyma, leading to fibrosis and cirrhosis [6].

CLD frequently associated with hematological abnormalities. Pathogenesis of hematological changes is multifactorial and included portal hypertension induce sequestration, alteration in bone marrow stimulating factors, viral and toxin-induced bone marrow suppression, and consumption or loss.

Anemia of diverse etiology occurs in about 75\% of patients of CLD [7]. Causes of anemia in CLD - iron deficiency, hypersplenism, anemia due to chronic disease, autoimmune hemolytic anemia, folic acid deficiency, aplastic anemia, and as an effect of antiviral drug. Alcohol is the most commonly used drug whose consequences include the suppression of hematopoiesis. These patients may suffer from nutritional deficiencies of folic acid and other vitamins due to malabsorption, malnutrition, or direct toxic effect that play a role in hematopoiesis. As a result, alcoholics may suffer from moderate-to-severe anemia, characterized by enlarged, structurally abnormal red blood cells (RBCs), mildly reduced numbers leukocytes and neutrophils, and moderately to severely reduced numbers of platelets [8].

Thrombocytopenia is common in CLD; mainly due to portal hypertension associated splenic sequestration, alteration in thrombopoietin, bone marrow suppression, consumptive coagulopathy, and increased blood loss. In CLD and cirrhosis, alterations in primary platelet hemostasis (platelet adhesion, activation and aggregation) have received less attention than changes in secondary hemostasis (coagulation). An increased intrasplenic platelet breakdown with variable roles of decreased platelet production and splenic pooling appears to be the most important determinants. Regarding the functional change, there is a decreased agreeability attributable to defective (transmembrane and intracellular) signaling, a storage pool defect, and an upregulation of the inhibitory pathways [9]. Thrombocytopenia is associated with increased bleeding tendency in CLD patients, so early detection of thrombocytopenia is important and helpful for decreased mortality and morbidity. 
Abnormalities in hematological indices are associated with increased risk of complications including bleeding and infection. Efforts can be made to normalize the hematological parameters so that the morbidity and mortality in this cirrhosis of liver patients could be effectively reduced. This could also extend help in increasing the longevity in transplant awaiting patients. We, through our study, have made an attempt to group the patients with deranged hematological indices and analyzed the variation of these indices in accordance. This could have clear therapeutic implications in managing these patients and reducing the adverse events.

\section{METHODS}

This observational study was carried out among 69 cirrhosis patients that fulfills the inclusion and exclusion criteria and attended the medicine outpatient department and admitted in medicine ward of Pandit Raghunath Murmu Medical College and Hospital (PRMMCH), Baripada, Dist. Mayurbhanj, Odisha, India, from June 2018 to January 2019.

\section{Inclusion criteria}

- All cirrhosis of liver patients above 15 years of age with stigmata of chronic liver cell failure on clinical examination substantiated by ultrasonography (USG) were included in the study.

\section{Exclusion criteria}

The following criteria were excluded from the study:

- Patients previously diagnosed to have one of the following causes of CLD

- Primary biliary cirrhosis

- Wilson's disease

- Hemochromatosis

- Primary sclerosing cholangitis.

- Patients of CLD presenting with associated comorbid diseases such as chronic renal failure and congestive heart failure

- Malignancy

- Pregnancy

- Previous history of hematological and coagulation disorder other than CLD

- Anemic patients already taking medications before being diagnosed as CLD.

After due consideration into inclusion and exclusion criteria, detailed history and clinical examination were undertaken in all subjects. Each subject instructed to have following investigations: Complete blood count (Sysmex XS-800i), USG abdomen, liver function tests, hepatitis B surface antigen, hepatitis $C$ virus antibody, serum urea, and creatinine. Twenty healthy persons were taken as controls.

In the present study, anemia was defined using the World Health Organization definition hemoglobin ( $\mathrm{Hb})$ concentration $<12 \mathrm{~g} / \mathrm{dl}$ (females) and $<13 \mathrm{~g} / \mathrm{dl}$ (males). The severity of anemia was classified as mild anemia (Hb concentration between 11-12.9 g/dl for males and 11-11.9 g/dl for females); moderate anemia ( $\mathrm{Hb}$ concentration between 8 and $10.9 \mathrm{~g} / \mathrm{dl}$ ), and severe anemia (Hb concentration $<8 \mathrm{~g} / \mathrm{dl}$ ) [10]. Thrombocytopenia was defined with a value of $<150 \times 10^{3} / \mu \mathrm{l}$.

\section{Statistical analysis}

All the data were fed on Excel spreadsheet, and statistical analyses were made using the SPSS version 21.0 software. Results were expressed in average \pm standard deviation, frequencies, and percentages. Continuous data were compared using Student's t-test. $\mathrm{p}<0.05$ was considered as statistically significant for all tests conducted.

\section{RESULTS}

During the study period, 69 patients with cirrhosis of liver admitted in medicine ward of PRMMCH, Baripada, fulfill inclusion and exclusion criteria. All the cases were studied for the clinical presentation, risk factors, and laboratory parameters
Fig. 1 shows out of 69 patients, 59 (85.51\%) were male and $10(14.49 \%)$ were female with $\mathrm{M}: \mathrm{F}$ of 5.9:1. The average age of the patients in the study was $49.8 \pm 13.19$ years. The average age of the male patient in the study was $50.05 \pm 13.04$ years. The average age of the female patients in the study was $48.3 \pm 14.74$ years. The age range was from 16 to 76 .

Table 1 shows that $55.07 \%$ of the patients were between 40 and 60 years of age.

Table 2 shows that $92.75 \%$ of the patients were alcoholic. Out of 10 female, nine gave alcohol history and out of 59 male, 55 were alcoholic.

Abdominal distension (92.75\%) and ascites (84.06\%) were the most common presenting complaints. Pallor was present in $42(60.87 \%)$ cases. Splenomegaly was present in $35(50.72 \%)$ patients of cirrhosis of liver. Renal dysfunction was present in 23 (33.33\%) cases. Four (5.8\%) patients presented with hematemesis and/or melena. One (1.45\%) presented with hepatic encephalopathy. The findings on clinical examination are listed in Table 3.

Fig. 2 shows hematological profile of cirrhosis of liver patients with mean $\mathrm{Hb}$ of $7.99 \pm 2.18 \mathrm{~g} / \mathrm{dl}$, of which $62(89.85 \%)$ patients had $\mathrm{Hb}$ $<11 \mathrm{~g} / \mathrm{dl}$ among which 37 (53.62\%) had $\mathrm{Hb} \leq 8 \mathrm{~g} / \mathrm{dl}$.

Table 4 shows that $66(95.65 \%)$ of the patients had anemia. Only three patients had $\mathrm{Hb}$ within normal range.

Table 5 shows that $47(68.12 \%)$ of the patients had decreased platelet count, out of which $23(33.33 \%)$ patients had $<1.0$ lakh/ml platelet count.

Fig. 3 shows that microcytic hypochromic anemia was predominant in cirrhosis patients. Macrocytic anemias were more common in males.

Table 6 shows the comparisons between hematologic indices of cirrhosis patients and healthy controls with significant association of anemia decreased RBC and thrombocytopenia in cirrhotic patients.

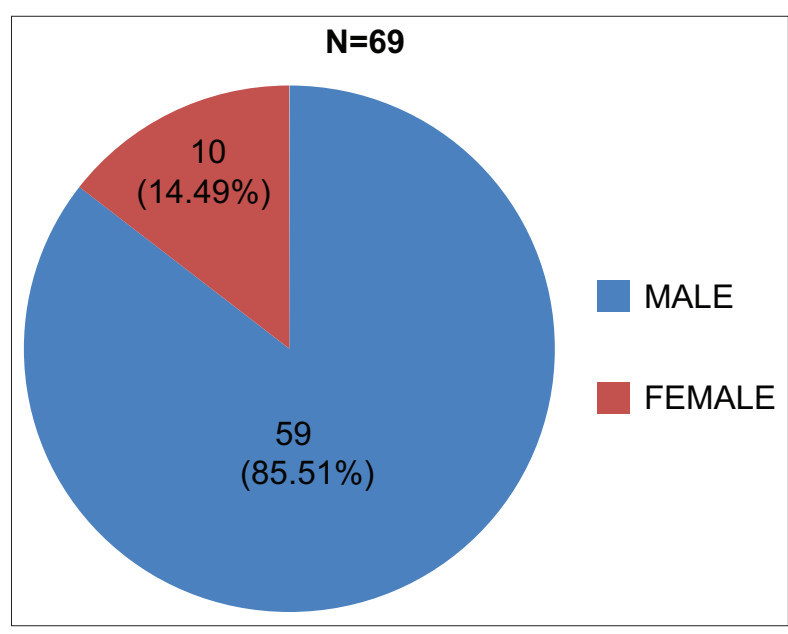

Fig. 1: Gender distribution

Table 1: Age distribution

\begin{tabular}{lllll}
\hline Age group & Male & Female & Total & \% \\
\hline$<20$ & 1 & 1 & 2 & 2.90 \\
$21-30$ & 5 & 0 & 5 & 7.25 \\
$31-40$ & 8 & 1 & 9 & 13.04 \\
$41-50$ & 21 & 3 & 24 & 34.78 \\
$51-60$ & 11 & 3 & 14 & 20.29 \\
$61-70$ & 11 & 2 & 13 & 18.84 \\
$71-80$ & 2 & 0 & 2 & 2.9 \\
Total & 59 & 10 & 69 & 100 \\
\hline
\end{tabular}


Table 2: Etiology of cirrhosis

\begin{tabular}{lll}
\hline Etiology & f & \% \\
\hline Alcoholic & 64 & 92.75 \\
Non-alcoholic & 5 & 7.25 \\
Hepatitis B & 0 & 0.00 \\
Hepatitis C & 0 & 0.00 \\
Total & 69 & 100 \\
\hline
\end{tabular}

Table 3: Symptoms and signs in cirrhosis of liver patients

\begin{tabular}{lll}
\hline Symptoms and signs & f & \% \\
\hline Pallor & 42 & 60.87 \\
Icterus & 14 & 20.29 \\
Edema & 26 & 37.68 \\
Asterixis & 1 & 1.45 \\
Ascites & 58 & 84.06 \\
Encephalopathy & 1 & 1.45 \\
Hematemesis & 3 & 4.35 \\
Melena & 4 & 5.80 \\
Splenomegaly & 35 & 50.72 \\
Renal dysfunction/decreased glomerular filtration rate & 23 & 33.33 \\
Abdominal distension & 64 & 92.75 \\
\hline
\end{tabular}

Table 4: Hemoglobin levels in cirrhosis of liver patients

\begin{tabular}{|c|c|c|c|c|c|c|}
\hline \multirow[t]{2}{*}{ Hemoglobin levels } & \multicolumn{2}{|c|}{ Male } & \multicolumn{2}{|c|}{ Female } & \multicolumn{2}{|c|}{ Total } \\
\hline & f & $\%$ & f & $\%$ & f & $\%$ \\
\hline Normal range & 2 & 3.39 & 1 & 10 & 3 & 4.35 \\
\hline $\begin{array}{l}\text { Mild }(11-12.9 \mathrm{~g} / \mathrm{dl} \text { in } \\
\text { males) and }(11-11.9 \mathrm{~g} / \\
\text { dl in females })\end{array}$ & 4 & 6.78 & 0 & 0 & 4 & 5.80 \\
\hline Moderate $(8-10.9 \mathrm{~g} / \mathrm{dl})$ & 21 & 35.6 & 4 & 40 & 25 & 36.23 \\
\hline Severe $(<8 \mathrm{~g} / \mathrm{dl})$ & 32 & 54.23 & 5 & 50 & 37 & 53.62 \\
\hline Total & 59 & 100 & 10 & 100 & 69 & 100 \\
\hline
\end{tabular}

Table 5: Platelet levels in cirrhosis of liver patients

\begin{tabular}{lll}
\hline Platelet count (lakh per $\mathbf{~ m l )}$ & f & \% \\
\hline$<1.5$ (thrombocytopenia) & 47 & 68.12 \\
$1.5-4.5$ & 21 & 30.43 \\
$>4.5$ & 1 & 1.45 \\
Total & 69 & 100 \\
\hline
\end{tabular}

\section{DISCUSSION}

Our study group consisted of 69 patients of cirrhosis of liver, out of which 59 (85.51\%) were male and $10(14.49 \%)$ were female with the age range from 16 to 76 . In our study, the average age of male patients was $50.05 \pm 13.04$ years and of female patients was $48.3 \pm 14.74$ years. The average age of the patients in the study was $49.8 \pm 13.19$ years, which is comparable with the study by Suthar et al. (41 years) [11] and Sarin et al. (43 \pm 8.7 years) [12]. In our study, M:F ratio was 5.9:1, which are due to the cultural and traditional influences in our country. About $55.07 \%$ of the patients were between 40 and 60 years of age, which shows a high prevalence of this disease among the productive age group. In our study, we found that $92.75 \%$ of the patients were alcoholic. Out of 10 female, nine gave alcohol history and out of 59 male, 55 were alcoholic.

In our study, abdominal distension (92.75\%) and ascites (84.06\%) were the most common presenting complaints.

Ascites was also a common finding in the previous studies; Suthar et al. (60\%) [11], Pathak et al. (57.5\%) [13], and Mendenhall (50.9\%) [14]. Splenomegaly was present in 35 (50.72\%) patients of cirrhosis of liver

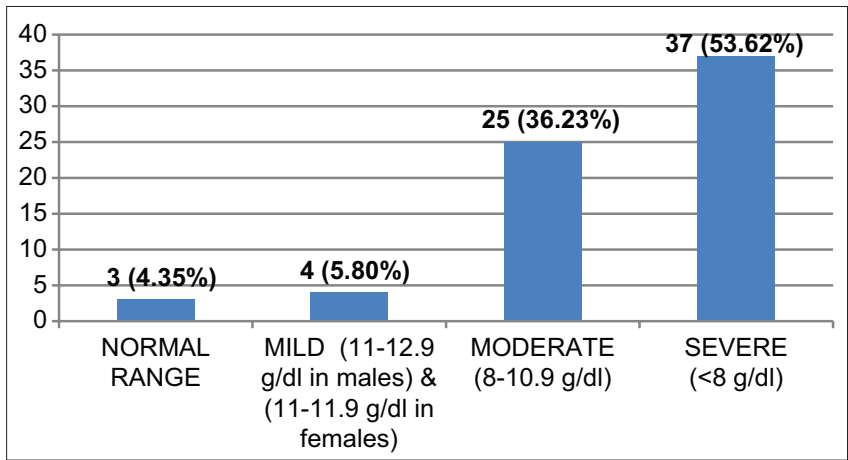

Fig. 2: Severity of anemia in cirrhosis of liver patients

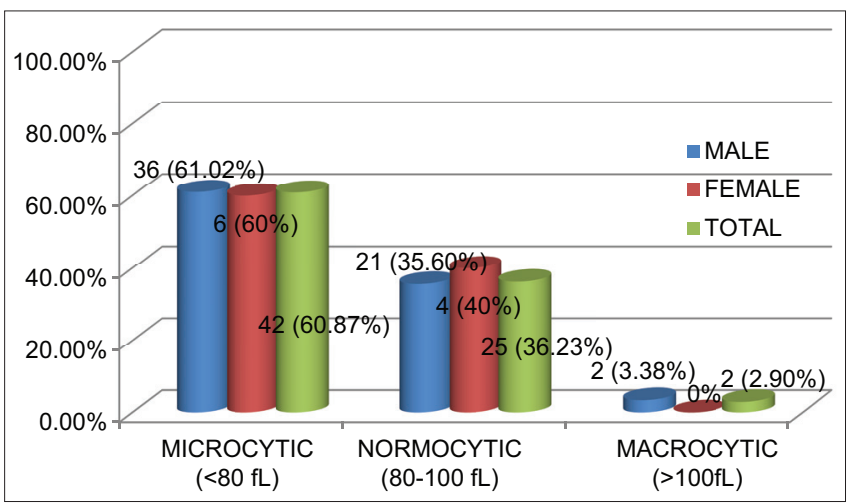

Fig. 3: Types of anemia in cirrhosis of liver patients

in our study.

In a study by Suthar et al. [11], splenomegaly was seen in $60 \%$ of cases. Only $1(1.45 \%)$ case presented with hepatic encephalopathy.

In our study, the blood urea was raised ( $>40 \mathrm{mg} / \mathrm{dl}$ ) in $36.23 \%$ (25 cases) of the patients, indicating indirectly toward acute renal injury (49.1\% in a study by Pathak et al. [13] and $37 \%$ in a study by Hegde et al. [15]).

In our study, the creatinine was raised in 22 patients (i.e., $31.88 \%$ of the study group) which were comparable with $39.4 \%$ in a study by Pathak et al. and $20 \%$ in a study by Hegde et al. It was observed that 23 patients had glomerular filtration rate (GFR) $<60 \mathrm{ml} / \mathrm{min}$; thus, $33.33 \%$ of the patients had significantly reduced GFR. Hegde et al. studied that $30 \%$ of the patients had significantly reduced GFR.

The mean $\mathrm{Hb}$ level in our study was $7.99 \pm 2.18 \mathrm{~g} \%$, whereas in other studies, the findings were as Hegde et al. (9.12 g\%). In our study, we found that 66 (95.65\%) of the patients had anemia, out of which $37(53.62 \%)$ had $\mathrm{Hb} \leq 8 \mathrm{~g} / \mathrm{dl}$, i.e. severe anemia. A study by GonzalezCasas et al. [16] showed that anemia in CLD patients was 75\%. Hegde et al. study also found severe anemia in $43 \%$ of cases. In our study, $36.23 \%$ had normal mean corpuscular volume, $60.87 \%$ has microcytic blood picture, and $2.9 \%$ had macrocytic blood picture. Macrocytic anemia was more common in males than females. Microcytic hypochromic anemia was predominant in cirrhosis patients. This may be due to the low socioeconomic and poor nutritional status of most of the cases in this part of Odisha.

According to interesting article by Kujovich MD - "Hemostatic defects in end-stage liver disease," critical care clinics 21 (2005) [17], mild-to-moderate thrombocytopenia occurs in $49-64 \%$ of patients with decompensated CLD. In our study, 47 (68.12\%) patients had thrombocytopenia $(<1.5$ lakhs $/ \mathrm{mm} 2)$, out of which 23 (33.33\%) patients had $<1.0$ lakh/ml platelet count. 
Table 6: Comparisons between hematologic indices of cirrhosis patients and controls

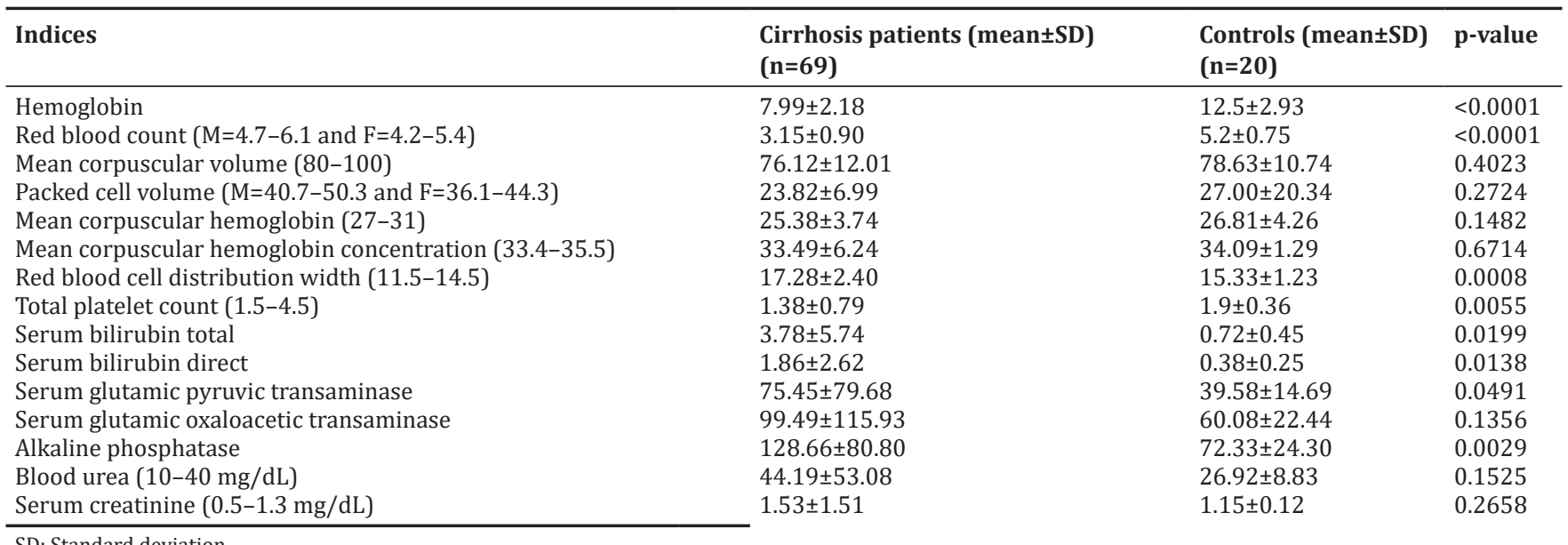

In our study, the hematological parameters ( $\mathrm{Hb}, \mathrm{RBC}$, and platelet) in cirrhosis of liver patients were statistically significant $(\mathrm{p}<0.05)$ (Table 6).

\section{CONCLUSIONS}

Many conclusive results regarding the hematological abnormalities in cirrhosis of liver were obtained with this limited study involving 69 patients with decompensated cirrhosis. The results of this study established most of the known facts about chronic alcoholic liver disease in this part of the world. Numerous clinical observations support the notion that alcohol adversely affects the production and functioning of virtually all types of blood cells. Long-term excessive alcohol consumption leads to liver cirrhosis which interferes with various physiological, biochemical, and metabolic processes involving the blood cell production and maturation, leading to these adverse effects. Not only liver function tests, patients with alcoholic liver disease have abnormal hematological and renal function too. Renal dysfunction is common in alcoholic liver disease, especially in patients with ascites. From this study, we can conclude that, in cirrhosis of liver patients, various hematological changes are very common which need to be identified and corrected early to reduce morbidity and mortality.

\section{ACKNOWLEDGMENTS}

Authors would like to thank Dr. Arunima Pattanaik, Dr. Sambit Parida, Dr. Soumyasmruti Parida, Nibedita Mantry, Swarnalata Samal, Saraswati Sahoo, Rubina Soren, Mamata Nayak, and Suchismita Patra, staffs of the Department of Medicine, PRMMC, Baripada, Odisha, India, for their cooperation in collecting the data for this study.

\section{AUTHORS' CONTRIBUTIONS}

Dr. Bibhu Prasad Behera, Assistant Professor in Medicine, Department of Internal Medicine, Saheed Laxman Naik Medical College and Hospital, Koraput, Odisha, is the primary investigator. Dr. Manoranjan Dash, Assistant Professor in Pulmonary Medicine, Saheed Laxman Naik Medical College and Hospital, Koraput, Odisha, is the corresponding author.

\section{CONFLICTS OF INTEREST}

None.

\section{AUTHORS' FUNDING}

No funding resource.

\section{ETHICAL APPROVAL}

Not required.

\section{REFERENCES}

1. Melato M, Sasso F, Zanconati F. Liver cirrhosis and liver cancer. A study of their relationship in 2563 autopsies. Zentralbl Pathol 1993;139:25-30.

2. Graudal N, Leth P, Mårbjerg L, Galløe AM. Characteristics of cirrhosis undiagnosed during life: A comparative analysis of 73 undiagnosed cases and 149 diagnosed cases of cirrhosis, detected in 4929 consecutive autopsies. J Intern Med 1991;230:165-71

3. Lim YS, Kim WR. The global impact of hepatic fibrosis and end-stage liver disease. Clin Liver Dis 2008;12:733-46.

4. Mathers C, Lopez A, Murray C. The burden of disease and mortality by condition: Data, methods, and results for 2001. In: Lopez A, Mathers C, Ezzati M, Jamison DT, Murray CJ, editors. Global Burden of Disease and Risk Factors. Washington, DC: Oxford University Press and the World Bank; 2006. p. 45-93.

5. Murray CJ, Lopez AD. Alternative projections of mortality and disability by cause 1990-2020: Global burden of disease study. Lancet 1997;349:1498-504.

6. Ashraf S, Naeem S. Frequency of hypersplenism in chronic liver disease patients presenting with pancytopenia. Spec Ed Ann 2010;16:108-10.

7. Khare S, Garg VK, Jain HK, Jatav O. To study hematological profile in patients of chronic liver disease. Int $\mathbf{J}$ Multidiscip Res Dev 2015;2:378-81.

8. Ballard HS. The hematological complications of alcoholism. Alcohol Health Res World 1997;21:42-52.

9. Shittu BT, Shittu MO, Oluremi AS, Orisadare O, Osemeke J, Lateef B. Thrombocytopenia and prolonged prothrombin time in neonatal septicemia. J Med Sci Clin Res 2014;2:1213-21.

10. World Health Organization. Hemoglobin Concentrations for the Diagnosis of Anemia and Assessment of Severity. Vitamin and Mineral Nutrition Information System (WHO/NMH/NHD/MNM/11.1). Geneva: World Health Organization; 2011. Available from: http://www. who.int/vmnis/indicators/hemoglobin. [Last accessed on 2019 Dec 24].

11. Suthar HN, Suthar KD, Mewada BN. Clinical profile of cases of alcoholic liver disease. Int J Med Sci Public Health 2013;2:394-8.

12. Sarin SK, Dhingra N, Bansal A, Malhotra S, Guptan RC. Dietary and nutritional abnormalities in alcoholic liver disease: A comparison with chronic alcoholics without liver disease. Am J Gastroenterol 1997;92:777-83.

13. Pathak OK, Paudel R, Panta OB, Pant HP, Giri BR, Adhikari B. Retrospective study of the clinical profile and prognostic indicators in patients of alcoholic liver disease admitted to a tertiary care teaching hospital in Western Nepal. Saudi J Gastroenterol 2009;15:171-5.

14. Mendenhall CL. Alcoholic hepatitis. Clin Gastroenterol 1981;10:417-41.

15. Hegde S, Vishnar A, Ramteke GB. Study of clinical and laboratory profile in alcoholic liver disease with emphasis on renal function. Int J Res Med Sci 2015;3:446-50.

16. Gonzalez-Casas R, Jones EA, Moreno-Otero R. Spectrum of anemia associated with chronic liver disease. World J Gastroenterol 2009; $15: 4653-8$.

17. Kujovich JL. Hemostatic defects in end stage liver disease. Crit Care Clin 2005;21:563-87. 